\title{
Characterization Of Activated Carbon Prepared From Coconut Shell Using Various Reagents For A Low Cost Water- Filter
}

\author{
Sohan Ahmed ${ }^{1}$, Vaibhav V Mada ${ }^{1}$, Vaibhav Kamath ${ }^{1}$, Gautham P Jeppu ${ }^{2}$ \\ ${ }^{1}$ UG Student. Chemical Engineering, Manipal Institute of Technology, Manipal, Karnataka, India \\ sohan.ahmedmit@gmail.com \\ vaibhavmada11@gmail.com \\ vaibhav.kamath1996@gmail.com \\ ${ }^{2}$ Associate Professor, Department of Chemical Engineering, Manipal Institute of Technology, Karnataka, India \\ gautham.jeppu@gmail.com
}

Abtract--The chemical and physical conditions used in the synthesis of activated carbon, an adsorbent used in water filtration,influence the specific surface area andporosity. In this paper, coconut shells werethe raw material and activation reagents such as Hydrochloric acid, Zinc Chloride and Phosphoric Acid were used. A single and double burn procedurewas carried out for each method. The activated carbon obtained was compared in terms of absorption capacity, bulk density, BET surface area and pore volume. The best results were yielded for activated carbon prepared withphosphoric acid using the single burn technique.

Keywords: Activated carbon, Adsorption, Hydrochloric acid, Phosphoric acid, Zinc chloride

\section{INTRODUCTION}

Activated carbon has been known as one of the highly reliable adsorbents for removal of contaminants from liquidsdue to its properties such as a large specific surface area and large pore volume that can provide high adsorption capacity, porous interiors and excellent mechanical properties. Adsorption on activated carbon is reliable because of its simple operation, and easy handling without any hazardous conditions.

The most common forerunners for the preparation of activated carbon are organic substances rich in carbon. These include agricultural wastes such as Tea waste, Apple waste, Banana peels, Coconut shells, Bagasse and Sawdust and fossils such as bituminous coal and by destructive distillation of bones.

In this study, coconut shell was used for production of activated carbon and the different methods of activation were studied to find the best activating reagent, since coconut shells are a waste material available at cheap rates in India and are abundant in nature.

Activated carbon is produced either by physical or chemical activation. Physical activation involves carbonization followed by steam or carbon dioxide activation whereas chemical activation involves carbonization followed by chemical activationby reagents such as $\mathrm{H}_{3} \mathrm{PO}_{4}, \mathrm{ZnCl}_{2}$ and $\mathrm{HCl}$.

In our study, chemical activation method using single burn and double burn techniques was used and the methods were compared.

\section{A. Chemical impregnation:}

\section{PARAMETERS FOR ACTIVATION}

The coconut shell was broken down into fine bits by a hammer and it was ensured that all crushed particles obtained were of a size range of $3-5 \mathrm{~mm}^{[5]}$. These particles were then placed in crucibles, each crucible having around 50 grams of the crushed shells. The particles were further grounded using a household mixer grinder to a size of around $1 \mathrm{~mm}$.

For the Double-Burn technique, carbonization in the furnace was carried out at a temperature of $450^{\circ} \mathrm{C}$ ${ }^{[2]}$ and then impregnation was done followed by a second carbonization, while for the Single-Burn technique chemical impregnation was carried out first and then the samples were carbonized.

Different activation agents were used for impregnation, which include Hydrochloric acid, Zinc chloride and Phosphoric acid, all of them at $25 \%$ concentration. The crucibles were kept at room temperature in a dry and dark place for a period of 24 hours to facilitate impregnation of the chemicals into the shells. The chemical agents are dehydrating agents that penetrate deep into the structure of the carbon rich shells forming pores within them. Pores affect the specific surface area as larger number of tiny pores will result in a larger specific surface area. 


\section{B. Activation Duration:}

The activation duration for the coconut shells have a pronounced effect on the formation of pores and hence, development of maximum specific surface area. The duration should be adequate to allow for the evaporation of all moisture and volatile matter in the raw shells.

In the Single-Burn technique, the samples were carbonized over a period of 30 minutes in an inert furnace at a temperature of $450^{\circ} \mathrm{C}^{[2]}$. Inert conditions were maintained by supply of $\mathrm{N}_{2}$ gas during the activation $^{[1]}$.In the Double-Burn technique, the coconut shells were once burnt at $450^{\circ} \mathrm{C}$ for a period of 20 minutes followed by chemical impregnation using $25 \% \mathrm{HCl}, \mathrm{ZnCl}_{2}$ and $25 \% \mathrm{H}_{3} \mathrm{PO}_{4}$ for 24 hours and a secondburn stage for another 20 minutes was carried out at $450^{\circ} \mathrm{C}$. It was observed that smoke containing volatile matter stopped evolving after 10-12 minutes of placing the samples in the furnace for the first time, and thus it might be inferred that the minimum time duration required for activation ranges between 15 to 20 minutes.

Out of these six experiments, highest BET specific surface area and pore volume was observed for the $\mathrm{H}_{3} \mathrm{PO}_{4}$ impregnatedSingle-Burn technique.

\section{METHODS USED}

\section{A. Filtration and $\mathrm{pH}$ adjustment:}

The samples prepared by both the Single-Burn and Double-Burn techniques were filtered using distilled water, 8-10 times through ordinary filter paper and the filtrate $\mathrm{pH}$ was checked after every two filtrations until the $\mathrm{pH}$ of the filtrate varied between 6.5 to $6.8^{[2]}$. The initial filtrate had a $\mathrm{pH}$ in the range 3.9 to 4.7 . The samples that did not reach a $\mathrm{pH}$ in the specified range were treated with $1 \% \mathrm{w} / \mathrm{v}$ Sodium bicarbonate solution $^{[3]}$ and filtered with the solution and again with distilled water until the $\mathrm{pH}$ was adjusted. The conductance of the filtrate too was checked and was found to be lower than that of tap water, which clearly indicated a low concentration of ions.

\section{B. Drying and Crushing:}

The samples were dried in a closed oven at $100^{\circ} \mathrm{C}^{[5]}$ for 24 hours after being filtered, to remove all traces of moisture. The particles were then crushed using a mortar and pestle and sieved through a sieve set consisting of 180, 125 and $90 \mu$ mesh size at regular intervals and then shaken in a sieve shaker. This was carried out till the size was below $125 \mu$ so as to facilitate for more surface area with smaller size of particles.

\section{Adsorption Test using Methylene Blue solution:}

A stock solution of Methylene blue dyeof $1000 \mathrm{ppm}$ was prepared by dissolving $1.0 \mathrm{~g}$ of Methylene blue dye powder in 1 liter of distilled water and stored in a 1 liter standard flask to be used for all tests pertaining to methylene blue adsorption.

The stock solution was used to prepare $100 \mathrm{ml}$ standard solutions of $62.5 \mathrm{ppm}, 125 \mathrm{ppm}, 187.5 \mathrm{ppm}$ and $250 \mathrm{ppm}$ in stoppered conical flasks for the single and double burn samples, both methods being used for each of the $\mathrm{HCl}$, $\mathrm{ZnCl}_{2}$ and $\mathrm{H}_{3} \mathrm{PO}_{4}$ activated carbon samples. $0.25 \mathrm{~g}$ Activated carbon was added to each sample so as to allow for adsorption capacities of $25 \mathrm{mg} / \mathrm{g}, 50 \mathrm{mg} / \mathrm{g}, 75 \mathrm{mg} / \mathrm{g}$ and $100 \mathrm{mg} / \mathrm{g}$. The solutions with the activated carbon samples were shaken in a rotary shaker at $150 \mathrm{rpm}^{[3]}$ for duration of 24 hours. Care was taken that the entire mass of the carbon sample was in the methylene blue solution and nothing stuck to the glass surface above the level of the methylene blue solution in each flask. A qualitative result of the changes observed in each flask is given in the table below.

Table I. Changes in color observed for Activated Carbon prepared by Single-burn technique

\begin{tabular}{|l|c|c|}
\hline $\begin{array}{c}\text { Reagent } \\
\text { Used }\end{array}$ & $\begin{array}{c}\text { Concentration of } \\
\text { Methylene Blue (ppm) }\end{array}$ & $\begin{array}{c}\text { Observation (change of } \\
\text { color of methylene blue) }\end{array}$ \\
\hline $\mathrm{HCl}$ & 62.5 & Significant change \\
\hline $\mathrm{HCl}$ & 125 & Insignificant change \\
\hline $\mathrm{HCl}$ & 187.5 & No changes observed \\
\hline $\mathrm{HCl}$ & 250 & No change \\
\hline $\mathrm{ZnCl}_{2}$ & 62.5 & Decolorized \\
\hline $\mathrm{ZnCl}_{2}$ & 125 & Significant change \\
\hline $\mathrm{ZnCl}_{2}$ & 187.5 & Insignificant change \\
\hline $\mathrm{ZnCl}_{2}$ & 250 & No change \\
\hline $\mathrm{H}_{3} \mathrm{PO}_{4}$ & 62.5 & Decolorized \\
\hline $\mathrm{H}_{3} \mathrm{PO}_{4}$ & 125 & Decolorized \\
\hline $\mathrm{H}_{3} \mathrm{PO}_{4}$ & 187.5 & Decolorized \\
\hline $\mathrm{H}_{3} \mathrm{PO}_{4}$ & 250 & Decolorized \\
\hline
\end{tabular}


Table II. Changes in color observed for Activated Carbon prepared by Double-burn technique

\begin{tabular}{|l|c|c|}
\hline $\begin{array}{c}\text { Reagent } \\
\text { Used }\end{array}$ & $\begin{array}{c}\text { Concentration of } \\
\text { Methylene Blue (ppm) }\end{array}$ & $\begin{array}{c}\text { Observation (change of color } \\
\text { of methylene blue) }\end{array}$ \\
\hline $\mathrm{HCl}$ & 62.5 & Insignificant change \\
\hline $\mathrm{HCl}$ & 125 & No change \\
\hline $\mathrm{HCl}$ & 187.5 & No change \\
\hline $\mathrm{HCl}$ & 250 & No change \\
\hline $\mathrm{ZnCl}{ }_{2}$ & 62.5 & Insignificant change \\
\hline $\mathrm{ZnCl}_{2}$ & 125 & Insignificant change \\
\hline $\mathrm{ZnCl}_{2}$ & 187.5 & No change \\
\hline $\mathrm{ZnCl}_{2}$ & 250 & No change \\
\hline $\mathrm{H}_{3} \mathrm{PO}_{4}$ & 62.5 & Almost decolorized \\
\hline $\mathrm{H}_{3} \mathrm{PO}_{4}$ & 125 & Slight change \\
\hline $\mathrm{H}_{3} \mathrm{PO}_{4}$ & 187.5 & No change \\
\hline $\mathrm{H}_{3} \mathrm{PO}_{4}$ & 250 & No change \\
\hline
\end{tabular}

From the observations in Table I and Table II it can be inferred that Single-burn technique is a more convenient technique than the Double-burn technique since the single burn phosphoric acid method decolorized the highest concentration of methylene blue solution

\section{BET Surface Area and Pore Volume Determination:}

Each of the samples obtained for the three reagents were subjected to tests in a BET Surface Area Analyzer (model Smart Sorb 92/93) after all moisture was removed in a regenerator. The results obtained clearly indicate that Single-burn technique was the more reliable technique and $\mathrm{H}_{3} \mathrm{PO}_{4}$ was the most efficient activation agent in the activation of carbon prepared from coconut shells.

Table III. Surface Area and Pore Volume of Activated Carbon prepared by Single-burn technique

\begin{tabular}{|l|c|c|}
\hline $\begin{array}{c}\text { Activation } \\
\text { agent }\end{array}$ & $\begin{array}{c}\text { Surface Area } \\
\left.\text { ( } \mathbf{m}^{2} / \mathbf{g m}\right)\end{array}$ & $\begin{array}{c}\text { Pore Volume } \\
\text { (cc/gm) }\end{array}$ \\
\hline $\mathrm{HCl}$ & 22.00 & 0.0212 \\
\hline $\mathrm{ZnCl}_{2}$ & 250.81 & 0.1501 \\
\hline $\mathrm{H}_{3} \mathrm{PO}_{4}$ & 779.29 & 0.4234 \\
\hline
\end{tabular}

Table IV. Double-burn technique

\begin{tabular}{|l|c|c|}
\hline $\begin{array}{c}\text { Activation } \\
\text { agent }\end{array}$ & $\begin{array}{c}\text { Surface Area } \\
\left(\mathbf{m}^{2} / \mathbf{g m}\right)\end{array}$ & $\begin{array}{c}\text { Pore Volume } \\
\text { (cc/gm) }\end{array}$ \\
\hline $\mathrm{HCl}$ & 112.61 & 0.0450 \\
\hline $\mathrm{ZnCl}_{2}$ & 112.04 & 0.0580 \\
\hline $\mathrm{H}_{3} \mathrm{PO}_{4}$ & 13.55 & 0.0098 \\
\hline
\end{tabular}

The determination of the specific surface area and pore volume further signifies without doubt the fact that single-burn phosphoric acid activation is the most reliable technique as adsorption capacity is directly proportional to the pore volume and the specific surface area.

If a line of best fit is plotted for BET Specific Surface area against Pore Volume for all the three activation agents, it turns out to be a straight line for both the Single-Burn and Double-Burn methods. (Figure 1 and 2) 


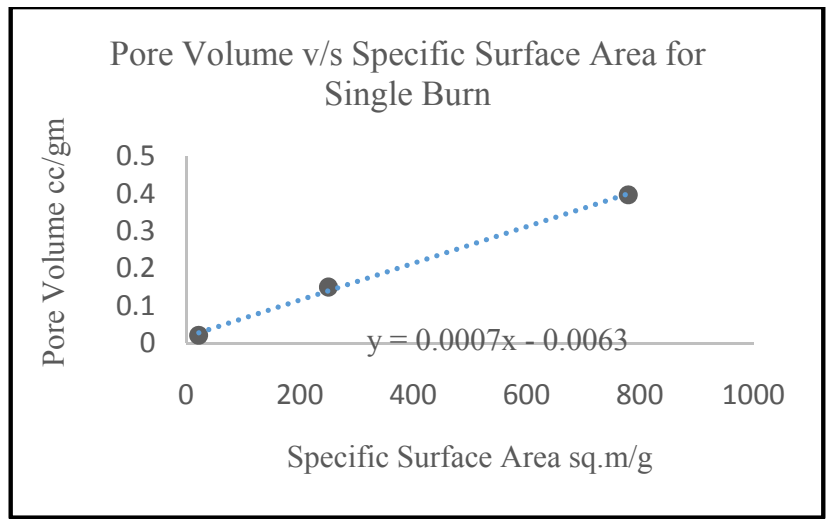

Figure 3. Plot of Pore Volume versus Specific Surface Area for Single-Burn Activated Carbon

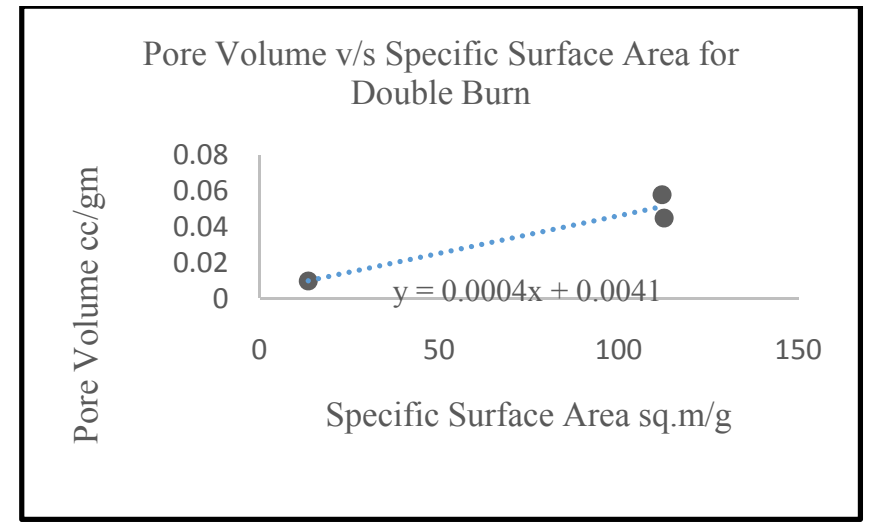

Figure 4. Plot of Pore Volume versus Specific Surface Area for Double-Burn Activated Carbon

As seen for the two plots (Figure 4 and 5) the higher values of both Pore Volume and Specific Surface Area are obtained for the Single-burn samples of Activated carbon and considering the case of Phosphoric Acid, Singleburn Pore Volume and Specific Surface Area is several times more than that of the Double-burn Phosphoric acid Activated carbon samples.

\section{METHYLENE BLUE VALUE OF THE ACTIVATED CARBON SAMPLES}

The color change of the methylene blue solution in the methylene blue adsorption tests gives an indirect indication of the adsorption capacity of the activated carbon samples. The Methylene Blue value is the milligrams of methylene blue adsorbed by each gram of activated carbon. Thus the concentration of the solution after 24 hours of shaking can be used to estimate the range of methylene blue value for each of the samples.

For the Single-burn samples, $\mathrm{HCl}$ activated carbon has a methylene blue (M.B) value of less than 25, $\mathrm{ZnCl}_{2}$ activated carbon has an M.B value in the range of 25-50, while the $\mathrm{H}_{3} \mathrm{PO}_{4}$ has a M.B value far superior to the others, i.e., well above 100.

For the Double-burn samples, $\mathrm{HCl}$ and $\mathrm{ZnCl}_{2}$ activated carbon have an M.B value far below than 25, and $\mathrm{H}_{3} \mathrm{PO}_{4}$ activated carbon has a M.B value just around 25 .

\section{CALCULATION OF METHYLENE BLUE VALUES}

The reason for choosing Methylene blue concentrations of $62.5 \mathrm{ppm}, 125 \mathrm{ppm}, 187.5 \mathrm{ppm}$ and 250ppm and using $100 \mathrm{ml}$ of each solution for a fixed mass of $0.25 \mathrm{~g}$ of Activated carbon can be mathematically demonstrated with the example -

Suppose for a 187.5ppm Methylene blue solution,

$$
187.5 \mathrm{ppm}=187.5 \mathrm{mg} \text { in } 1000 \mathrm{ml}
$$

Or, $187.5 \mathrm{ppm}=18.75 \mathrm{mg}$ in $100 \mathrm{ml}$

If the $0.25 \mathrm{~g}$ of mass activated carbon adsorbs the entire colour of the solution, thus $0.25 \mathrm{~g}$ adsorbs $18.75 \mathrm{mg}$ methylene blue. Hence $1 \mathrm{~g}$ of activated carbon will adsorb $\left(18.75^{*} 4=\right) 75 \mathrm{mg}$ methylene blue, or the adsorption capacity in terms of M.B value will be 75 .

Similarly for $62.5 \mathrm{ppm}, 125 \mathrm{ppm}$ and $250 \mathrm{ppm}$ Methylene blue concentrations, the corresponding adsorption capacities as M.B value would be 25, 50 and 100 . 
It was decided to prepare more closely spaced Methylene blue concentrations of solutions once the best activation agent along with the best activation technique (Single-burn or Double-burn) would be discovered and the range of values for its Methylene blue value would be known.

\section{STANDARD CALIBRATION CURVE AND EXACT METHYLENE BLUE VALUE DETERMINATION FOR $\mathrm{H}_{3} \mathrm{PO}_{4}$ ACTIVATED SAMPLE}

Since the Single-burn, $\mathrm{H}_{3} \mathrm{PO}_{4}$ activated sample has not only the highest BET Specific Surface Area and Pore Volume, but also decolorizes the higher concentrations of methylene blue solutions, quantitative tests were carried out to determine the exact adsorption capacity of the sample in terms of methylene blue value.

Since the Methylene blue value of activated carbon prepared using $\mathrm{H}_{3} \mathrm{PO}_{4}$ as the activation agent ranges above 100, a 1000ppm stock solution of Methylene blue was used to prepare 7 different stock solutions of concentrations 200ppm, 250ppm, 300ppm, 325ppm, 335ppm, 350ppm and 400ppm. Between 300ppm and $350 \mathrm{ppm}, 325 \mathrm{ppm}$ and $335 \mathrm{ppm}$ were selected to determine more accurately the M.B value.

The absorbance of the methylene blue solutions were measured in a UV Spectrometer at a set wavelength of $663 \mathrm{~nm}^{[3]}$ and the calibration curve of absorbance versus concentration of methylene blue solutions was plotted as shown in Figure 5.For the linearization of the standard calibration curve (Figure 5), the equation of the curve is given by:

$$
\mathrm{A}=0.1403 \mathrm{C}+0.0835
$$

Where, $\mathrm{A}$ is the absorbance as seen in the UV Spectrometer, and $\mathrm{C}$ the concentration of Methylene blue in ppm.

The standard Methylene blue solutions were then taken and $0.2 \mathrm{~g}$ of Activated carbon prepared by the Singleburn $\mathrm{H}_{3} \mathrm{PO}_{4}$ activation technique and put into $100 \mathrm{ml}$ of solution in conical flasks, of each of the 7 concentrations specified above. The solutions were then stoppered an kept in the rotary shaker for a period of 24 hours.

With the naked eye almost complete decolourization was observed for the 200ppm, 250ppm, and 300ppm Methylene blue solutions. The adsorbed solutions of 7 different concentrations were again subjected to absorbance tests using the UV Spectrometer to determine the exact Methylene blue value. The change in colour of the M.B solutions after being shaken with Activated carbon can be depicted in the absorbance versus concentration curve (Figure 6).

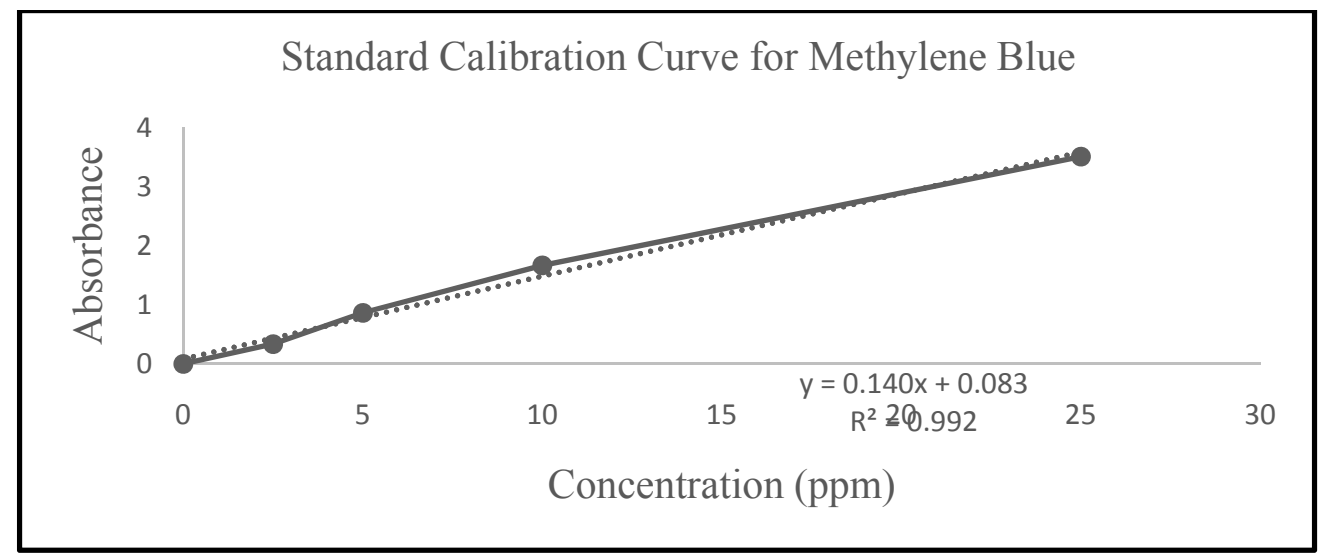

Figure 5. Standard calibration Curve for Methylene blue solution

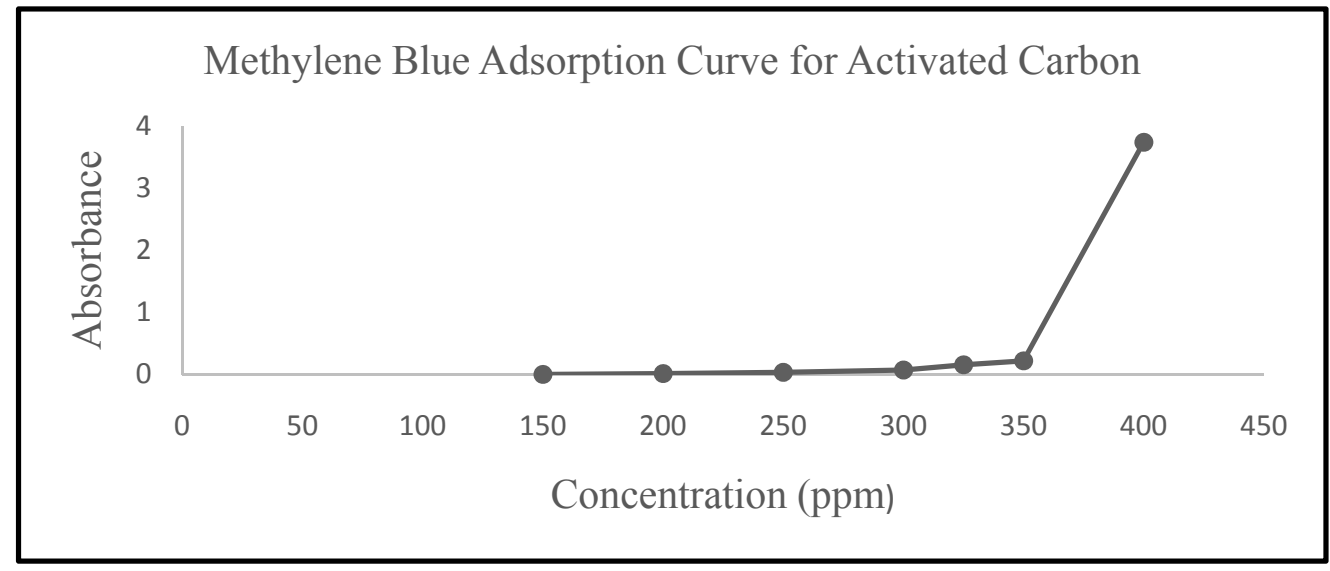

Figure 6. Absorbance versus concentration curve for Methylene blue solutions treated with Activated carbon 


\section{STUDY OF BATCH ADSORPTION TO IDENTIFY ADSORPTION ISOTHERM}

The Freundlich Isotherm has a general equation given as :

$$
\mathrm{q}_{\mathrm{e}}=\mathrm{K}_{\mathrm{f}} \mathrm{C}_{\mathrm{e}}{ }^{1 / n}
$$

where, $\mathrm{n}$ is a Freundlich constant related to adsorption efficiency and energy of adsorption, $\mathrm{K}_{\mathrm{f}}$ is a Freundlich constant measuring adsorption capacity, $\mathrm{q}_{\mathrm{e}}$ is amount of adsorbate adsorbed per unit weight of carbon.

The Langmuir Isotherm ${ }^{[7]}$ has a general equation given as:

$$
\left(\mathrm{C}_{\mathrm{e}} / \mathrm{q}_{\mathrm{e}}\right)=\left(1 / \mathrm{Q}_{\mathrm{o}} \mathrm{b}\right)+\left(\mathrm{C}_{\mathrm{e}} / \mathrm{Q}_{\mathrm{o}}\right)
$$

where $Q_{o}$ and $b$ are Langmuir constants related to adsorption capacity and energy of adsorption respectively ${ }^{[7]}$. The experiment was carried out using $0.1 \mathrm{~N}$ oxalic acid as adsorbate ${ }^{[8]} \cdot 0.1 \mathrm{~N} \mathrm{NaOH}$ was standardized after titrating it with oxalic acid ${ }^{[8]}$. 5 flasks with 1, 2, 3, 4, 5 grams of the single-burn $\mathrm{H}_{3} \mathrm{PO}_{4}$ and $150 \mathrm{ml}$ of oxalic acid in each was kept in the rotary shaker for 1 hour at 200rpm, the solutions were filtered and $10 \mathrm{ml}$ of each solution was titrated against the $\mathrm{NaOH}$.

Table 5. Experimental data to verify the adsorption isotherms

\begin{tabular}{|c|c|c|l|c|c|c|}
\hline $\begin{array}{l}\text { Amount of } \\
\text { AC added } \\
(\mathbf{W} \text { g) }\end{array}$ & $\begin{array}{l}\text { Titre } \\
\text { Value of } \\
\mathbf{N a O H} \\
\left(\mathbf{V}^{*} \mathbf{~ m l}\right)\end{array}$ & $\begin{array}{l}\text { Normality of } \\
\text { unadsorbed } \\
\text { acid } \mathbf{( N )}\end{array}$ & $\begin{array}{l}\text { Initial } \\
\text { concentration } \\
\text { of oxalic acid } \\
\mathbf{(}_{\mathbf{0}} \mathbf{g} / \mathbf{c m}^{\mathbf{3}} \mathbf{)}\end{array}$ & $\begin{array}{l}\text { Final } \\
\text { concentration } \\
\text { of oxalic acid } \\
\mathbf{( C}_{\mathbf{e}} \mathbf{g} / \mathbf{c m}^{\mathbf{3}} \mathbf{)}\end{array}$ & $\begin{array}{l}\text { Percentage } \\
\text { adsorption }\end{array}$ & $\mathbf{q}_{\mathbf{e}} \mathbf{( g / g )}$ \\
\hline 1 & 10.4 & 0.098072 & 0.0063 & 0.006179 & 1.928 & 0.01822 \\
\hline 2 & 10.2 & 0.096186 & 0.0063 & 0.006060 & 3.814 & 0.01802 \\
\hline 3 & 10.0 & 0.094300 & 0.0063 & 0.005941 & 5.700 & 0.01795 \\
\hline 4 & 9.8 & 0.092414 & 0.0063 & 0.005822 & 7.586 & 0.01792 \\
\hline 5 & 9.6 & 0.090528 & 0.0063 & 0.005703 & 9.472 & 0.01790 \\
\hline
\end{tabular}

Where, Percentage adsorption $=\left(\mathrm{C}_{\mathrm{o}}-\mathrm{C}_{\mathrm{e}}\right) / \mathrm{C}_{\mathrm{o}} * 100$,

Amount of oxalic acid adsorbed onto unit gram of activated carbon ${ }^{[6]}, \mathrm{q}_{\mathrm{e}}=\left(\mathrm{C}_{\mathrm{o}} \mathrm{C}_{\mathrm{e}}\right)^{*} \mathrm{~V}$

$\mathrm{V}=$ (Vol. of Oxalic acid used / Amount of Activated Charcoal taken) for shaking

The Freundlich constants obtained are $\quad \mathrm{k}_{\mathrm{f}}=0.0507$ and $\quad \mathrm{n}=4.9456$

The Langmuir Isotherm constants obtained are $Q_{0}=44.843$ and $\quad b=15.928$

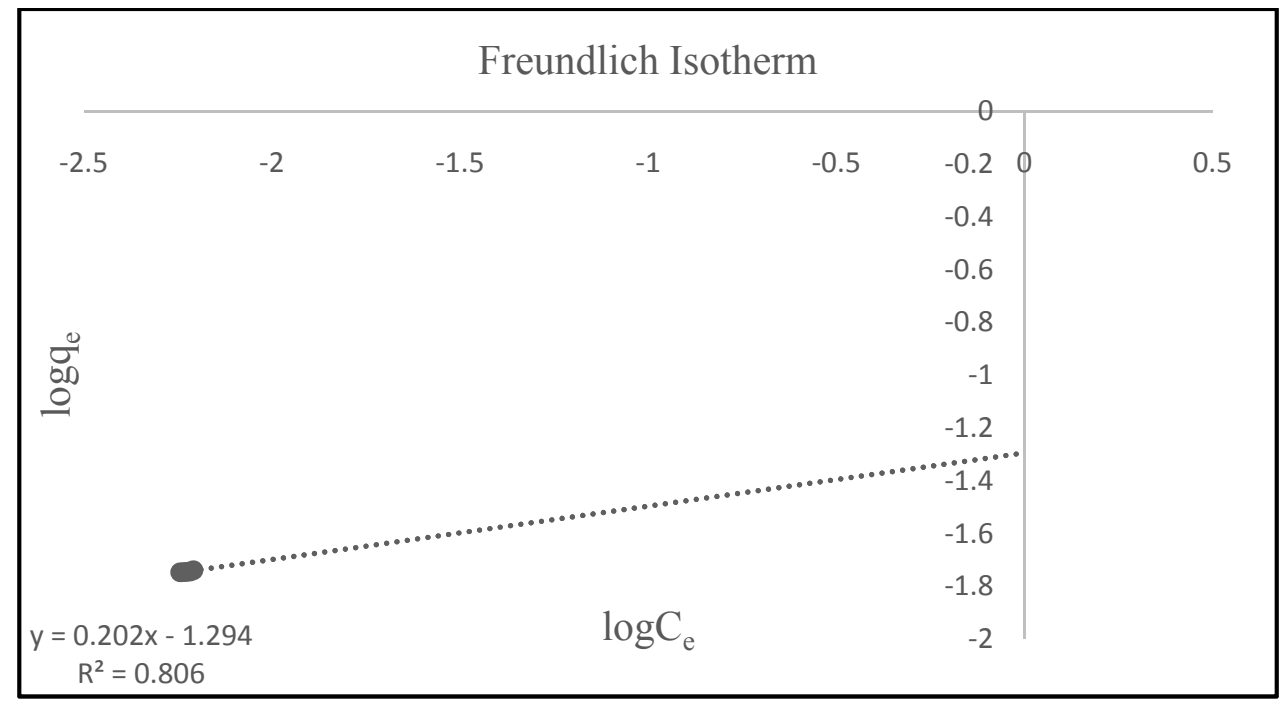

Figure 8. Linearlized plot of $\log \mathrm{q}_{\mathrm{e}} \mathrm{vs} \log \mathrm{C}_{\mathrm{e}}$ (Freundlich Isotherm) 


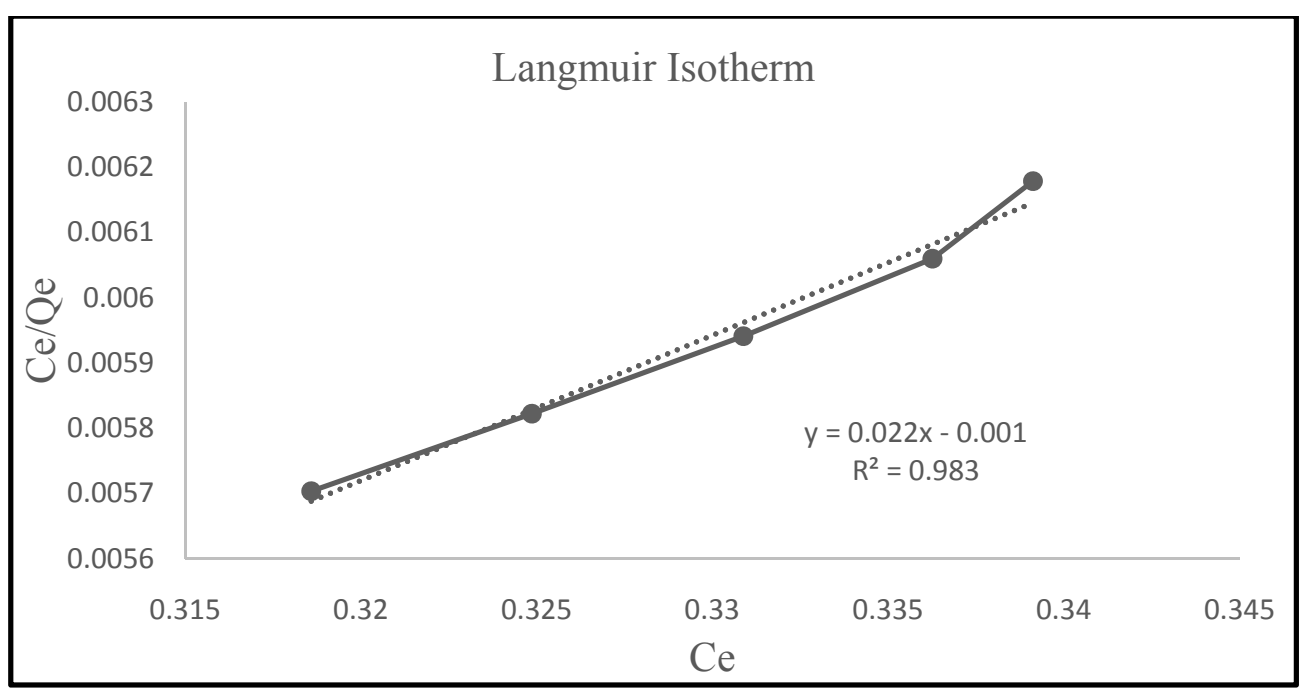

Figure 9. Plot of $\mathrm{C}_{\mathrm{e}} / \mathrm{q}_{\mathrm{e}}$ vs $\mathrm{C}_{\mathrm{e}}$ (Langmuir Isotherm)

VIII. ASH CONTENT

Since ash is a factor that undermines the adsorption capacity of activated carbon, the ash content of the Singleburn and Double burn samples exhibiting the highest surface area were found. The $\mathrm{HCl}$ activated carbon was chosen for the double-burn technique and the $\mathrm{H}_{3} \mathrm{PO}_{4}$ activated carbon sample for the single-burn technique.

Crucibles were taken and weighed before and after putting in the samples. Then they were placed in a muffle furnace and heated in the open atmosphere at $900^{\circ} \mathrm{C}$ for a period of 30 minutes for complete combustion of the combustible matter ${ }^{[4]}$. The mass of crucibles were then weighed and the Ash content found out using the relation -

$$
\text { Ash Content }{ }^{[4]}=\left[\left(\mathrm{M}_{\mathrm{pb}}-\mathrm{M}_{\mathrm{ec}}\right) /\left(\mathrm{M}_{\mathrm{bb}}-\mathrm{M}_{\mathrm{ec}}\right)\right] * 100
$$

where, $\mathrm{M}_{\mathrm{pb}}$ - mass of crucible + carbon post burning

$\mathrm{M}_{\mathrm{ec}}$ - mass of empty crucible

$\& \mathrm{M}_{\mathrm{bb}}$ - mass of crucible + carbon before burning

The Ash content was found to be $17.3 \%$ of the total mass for the Double burn sample and $1.686 \%$ of the total mass for the Single burn sample.

\section{BULK DENSITY}

The Bulk Density is a significant indicator of the packaging consistency of the powdered sample in terms of weight per volume. The single-burn $\mathrm{H}_{3} \mathrm{PO}_{4}$ activated carbon samples were placed till the $5 \mathrm{ml}$ mark in a dry $10 \mathrm{ml}$ measuring cylinder whose mass was weighed before and after placing the sample and drying it. Thea activated carbon was then placed in an oven for 60 minutes at $100^{\circ} \mathrm{C}$ and the mass was measured ${ }^{[4]}$. The Bulk Density was calculated as:

Bulk Density ${ }^{[4]}=($ Mass of A.C + Cylinderafterdrying - Mass of empty cylinder $) /($ Volume occupied $)$

$$
=(67.47-64.529) / 5=0.5882 \mathrm{~g} / \mathrm{cm}^{3}
$$

\section{RESULTS AND DISCUSSION:}

The comparison column chart in Figure10 below can be used to conclude what has been stated above. The original Methylene blue absorbance has been depicted to the left of each concentration abscissa while the Methylene blue absorbance after shaking withActivated carbon is to theright of each concentration. 


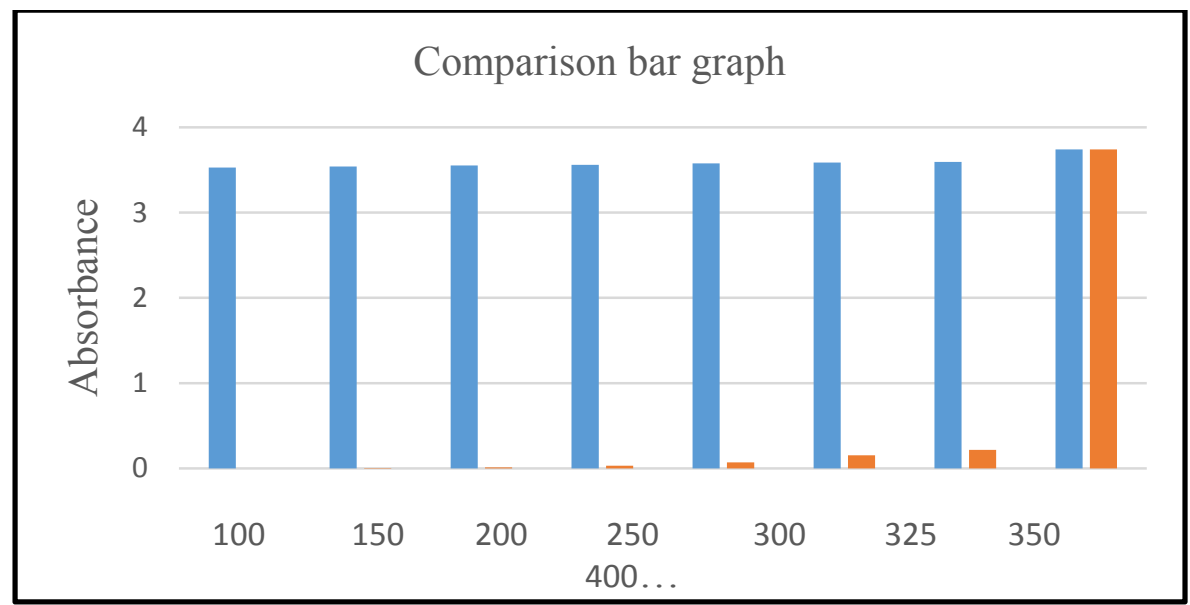

Figure 10. Column Chart to compare Adsorption of Methylene blue by Activated carbon at various concentrations

Thus it can be concluded that amidst the 3 different activating agents tested under two different types of carbonization, the best Activated carbon has been produced using $\mathrm{H}_{3} \mathrm{PO}_{4}$ as the activating agent in the Singleburn technique.

The Single-burn technique is more viable as it is not only economic and requires lesser expenditure of energy but also allows for less of undesirable ash content, as it has been the case using Double-burn technique. The Single-burn technique using an inert atmosphere allows for larger pores to develop, thus increasing the Pore Volume and Specific Surface Area.

As the absorbance of tap water was around 0.1, it may be safely concluded that the Methylene blue value of the $\mathrm{H}_{3} \mathrm{PO}_{4}$ activated carbon using the Single-burn carbonization technique lies between 150-155.

Table 6. Summary of parameters and properties for the $\mathrm{H}_{3} \mathrm{PO}_{4}$ Single-burn activated carbon

\begin{tabular}{cc}
\hline Parameter & Value \\
\hline Size of coconut shells post crushing & $3-5 \mathrm{~mm}$ \\
Duration of Chemical Impregnation & 24 hours \\
Concentration of acid used & $25 \%$ \\
Activation temperature & $450^{\circ} \mathrm{C}$ \\
Activation duration & 30 minutes \\
Duration of drying & 24 hours \\
pH of final filtrate & 6.8 \\
Particle size & $<125 \mu$ \\
BET Specific Surface Area & $779.29 \mathrm{~m}^{2} / \mathrm{gm}$ \\
Pore Volume & $0.3968 \mathrm{~cm}^{3} / \mathrm{gm}$ \\
Bulk Density & $0.5882 \mathrm{~g} / \mathrm{cm}^{3}$ \\
Ash content & $1.686 \% \mathrm{by} \mathrm{mass}$ \\
Methylene Blue Value & $150-155$ \\
\hline
\end{tabular}

We can thus conclude that among the three activation agents, namely Hydrochloric Acid, Phosphoric Acid and Zinc Chloride, Phosphoric acid is the best one in all the parameters tested for such as Methylene blue value, Specific Surface Area, Pore Volume and Ash Content.

The adsorption follows the Langmuir Isotherm as the correlation coefficient of 0.9838 is close to 1 as compared to 0.8061 for the Freundlich Isotherm. In our experiment the value of $n$ (4.9456),in Freundlich Isotherm being above 1 signifies good adsorption ${ }^{[8]}$.

In all cases, adjustment of $\mathrm{pH}$ after filtration is a necessary factor in order to subject the samples to Methylene blue tests and get positive results because Methylene blue itself being acidic repels $\mathrm{H}^{+}$ions in activated carbon, which occurs due to the chemical impregnation by acid. Hence the $\mathrm{pH}$ must be brought to the range of 5.8 to 7.0 either by repeated water washing and filtration or water wash by addition of $\mathrm{NaHCO}_{3}$ which is alkaline and filtration followed by filtration. 


\section{REFERENCES}

[1] O. Ioannidou, A. Zabaniotou, "Agricultural residues as precursors for activated carbon production-A review," Renewable and Sustainable Energy Reviews, Elseiver, 2006.

[2] M.K.B Gratuito, T. Panyathanmaporn, R.A Chumnanklang, N. Sirinuntawittaya, A Dutta, "Production of activated carbon from coconut shell : Optimization using response surface methodology," Bioresource Technology, Elseiver, 2007.

[3] Emad N. El Qada, Stephen Allen and Gavin M. Walker, "Adsorption of Methylene Blue onto activated carbon produced from steam activated bituminous coal: A study of equilibrium adsorption isotherm," Chemical Engineering Journal, Elseiver, 2006

[4] Smruthirekha Das, Sushmita Mishra, "Characterization of Activated Carbon of Coconut Shell, Rice Husk and Karanja Oil Cake," A thesis submitted to NIT Rourkela, Odisha, India, page 27-28, unpublished, 2014.

[5] Hoque M Mozammel, Ota Masahiro, Bhattacharya SC, "Activated charcoal from coconut shell using $\mathrm{ZnCl}_{2}$ activation," Biomass and Bioenergy Journal, Pergamon, 2001.

[6] Mulu Berhe Desta, "Batch Sorption Experiments: Langmuir and Freundlich Isotherm Studies for the Adsorption of Textile Metal Ions onto Teff Straw (Eragrostis tef) Agricultural Waste," Journal of Thermodynamics Volume 2013.

[7] R. Hema Krishna, A.V.V.S Swamy, "Physico-Chemical Key Parameters, Langmuir and Freundlich isotherm and Lagergren Rate Constant Studies on the removal of divalent nickel from the aqueous solutions onto powder of calcined brick," International Journal of Engineering Research and Development, 2012.

[8] Kavita S. Mundhe, "Adsorption Study of Oxalic Acid Using Biosorbents," International Journal of Applied Science and Mathematics, 2016. 